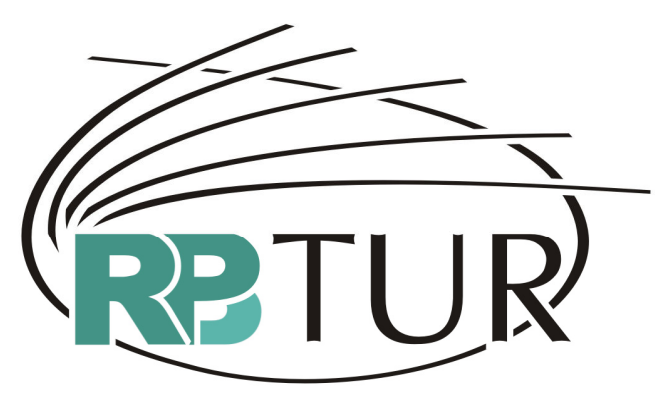

REVISTA BRASILEIRA DE PESQUISA EM TURISMO

\title{
ECONOMIA DA EXPERIÊNCIA: O CONSUMO DE EMOÇÕES NA "REGIÃO UVA E VINHO"
}

\author{
EXPERIENCE ECONOMY: CONSUMING EMOTIONS AT \\ "GRAPES AND WINE REGION"
}

\section{ECONOMÍA DE LA EXPERIENCIA: EL CONSUMO DE EMOCIONES EN LA "REGIÓN UVA Y VINO"}

Hernanda Tonini ${ }^{1}$

\begin{abstract}
RESUMO: O presente artigo traduz o turismo como mais uma forma de consumo da sociedade atual, revigorado pela recente divulgação dos conceitos da Economia da Experiência ou Sociedade dos Sonhos. A base do artigo partiu do projeto Economia da Experiência, implementado na Região Uva e Vinho, no Rio Grande do Sul, objetivando adequar a oferta local às novas estratégias de comercialização do enoturismo, atividade turística principal na região.
\end{abstract}

Palavras-chave: Economia da experiência. Consumo. Turismo. Enoturismo.

ABSTRACT: This article analyzes tourism as a consumers good in present societies, enhanced by concepts as Experience Economy or Dreams Society. It follows a project designated as Experience Economy, with implementation at "Grapes and Wine Region", Rio Grande do Sul State, which aims to fit local offer to new commercialization strategies in wine tourism, main local tourism attraction.

Key-words: Experience economy. Consumption. Tourism. Wine tourism.

RESUMEN: En este artículo se aborda el turismo como una forma más de consumo de la sociedad contemporánea, revitalizado con la reciente divulgación de los conceptos de Economía de la Experiencia o Sociedad de los Sueños. La base del artículo está en el proyecto Economía de la Experiencia, implantado en la Región Uva y Vino, en Rio Grande del Sur, que se propone adecuar la oferta local a las nuevas estrategias de

\footnotetext{
${ }^{1}$ Hernanda Tonini, Bacharel em Turismo (UNISUL-SC), Especialista em Gestão Empresarial (FGV-SC), Mestre em Turismo (UCS-RS). Atualmente docente da Faculdade Anglo Americano Passo Fundo e da Faculdade Ideau. E-mail: htonini@hotmail.com
} 
comercialización adoptadas por el enoturismo, principal actividad turística de la región.

Palabras-clave: Economía de la experiencia. Consumo. Turismo. Turismo enológico.

\section{Introdução}

Novas expressões idiomáticas surgem em todo momento com o propósito de identificar hábitos ou padrões que passam a existir na sociedade no decorrer dos anos. Com maior freqüência, pesquisas e estudos nos mais diversos campos revelam novas informações e situações que necessitam de termos específicos para serem reconhecidas pelas pessoas.

Neste contexto, surgiram os conceitos da Economia da Experiência (PINE; GILMORE, 1999) e da Sociedade dos Sonhos (JENSEN, 2002), tendências oriundas da ciência econômica que têm se difundido em diferentes setores, inclusive no turismo. A essência dos termos concentra-se na criação de experiências e emoções que o consumo de determinado produto propicia ao consumidor, oportunizando vivências individualizadas e, desta forma, singulares. O consumo de um produto satisfaz não apenas uma necessidade evidente, mas gera uma série de outras satisfações de âmbito subjetivo.

Com base nestas tendências, muitas organizações privadas e públicas iniciaram uma transição, buscando adequar produtos e serviços de modo a inseri-los em uma corrente cujo intuito é incrementar a comercialização (BENI, 2003). Todo este processo não deixa de fazer parte do modelo capitalista de produção, acumulação e consumo. O modelo que toma conta dos seres sociais, traduzido em uma nova síntese econômica: o consumo de emoções. É a busca constante pela geração de riqueza, estimulada pela possibilidade de consumir algo, a qualquer momento; a "arte" de reproduzir continuamente mais riqueza para manter-se sempre consumindo. A idéia da cultura de consumo é constantemente anunciada como nova e a cada geração os discípulos do capitalismo descobrem novas alternativas consideradas como uma inovação, quando na realidade fazem parte da história dos ser humano (SLATER, 2002). 
Partindo dos pressupostos da chamada Economia da Experiência, foi desenvolvido o Projeto Economia da Experiência - Vivências na Região Uva e Vinho, no Rio Grande do Sul, realizado pelo Ministério do Turismo, em parceria com o Sebrae Nacional e o Sindicato de Hotéis, Restaurantes, Bares e Similares da Região Uva e Vinho. Região esta que possui seu atrativo turístico principal explícito no próprio: o vinho e seu entorno, desde sua fabricação até a cultura do povo em si. Afinal, o que poderia ser mais singular que as sensações provocadas pelo aroma, o paladar, a paisagem, que um produto neste caso, o vinho - proporciona?

Utilizando-se destes argumentos, o projeto foi colocado em prática e será analisado a seguir, a partir da ótica do turismo como uma forma de consumo crescente na sociedade e, assim, parte do modelo capitalista e seus ajustamentos na época presente.

\section{A "nova" economia: Projeto Economia da Experiência - Vivências na Região Uva e Vinho}

$\mathrm{Na}$ atualidade, a grande preocupação dos setores econômicos é a perpetuação de sua hegemonia com os clientes perante os concorrentes. Constantemente, as empresas estão adequando hábitos, rotinas, serviços e produtos no intuito de conquistar uma fatia cada vez maior de um mercado até então em expansão. Com as empresas turísticas não ocorre de forma diferente.

Muitos estudos econômicos e de marketing informam que os desejos dos clientes de hoje são movidos por razões emocionais e não apenas racionais (SWARBROOKE; HORNER, 2002). Segundo Jensen (2002), vivemos atualmente no que denomina Sociedade do Sonho, pois um produto não contém apenas a função única pela qual foi produzido, mas vai além. Na Sociedade do Sonho, o consumo de um produto está associado ao valor emocional que o mesmo possui, não apenas ao produto físico em si e a 
possibilidade de satisfazer uma necessidade real (JENSEN, 2002). É o que Marcuse (1968) chama de "falsas necessidades". O tênis não é adquirido apenas para caminhar, mas também como forma de diferenciação, status, estilo. O mesmo ocorre com os carros, as casas, as viagens e outros.

O turismo, deslocamento temporário que o indivíduo faz por motivos diversos, é generoso ao unir a fantasia, o sonho e o diferente na experiência do chamado produto turístico, caracterizado como a combinação de bens e serviços que o viajante compra com o intuito de realizar sua viagem (JENKINS; LICKORISH, 2000). O produto turístico Disney, por exemplo, um conjunto de parques com serviços diversos, apresentações artísticas, entre outros, desenvolve todo o seu trabalho para que os "convidados" - assim são chamados os visitantes - desfrutem de uma experiência única, aliada à fantasia e ao sonho, tornando-se um acontecimento inesquecível (CONNELLAN, 2002).

Processo similar ocorre nos resorts, nas praias ditas paradisíacas, no contato com uma cultura diferente e por isso mesmo exótica, pois o que é comercializado não é o local apenas, mas também o conjunto de situações que podem ser vividas no momento do consumo. Conforme aponta Lemos (2005), o turismo não lida apenas com necessidades, mas também com desejos e sonhos; busca o suprimento das necessidades materiais e, além destas, das subjetivas.

Segundo Beni (2002), o turismo é um produto intangível, ou seja, não pode ser comprado e levado pra casa, e seu consumo ocorre simultâneo a sua produção. Desta forma, sua comercialização dispõe de imagens que pressupõem o que o turista poderá satisfazer conhecendo o local. Este tipo de consumo subjetivo, apontado por diferentes autores, é que possibilita um resultado diferente quanto ao produto, pois o mesmo é inteiramente influenciado pelas memórias e interesses de quem o consome, estando diretamente relacionado às formas de consumo relatadas por Jensen (2002) na Sociedade do Sonho. 
Pine e Gilmore (1999) batizaram de Economia da Experiência a forma de comercialização na qual o consumidor não adquire simplesmente um produto ou serviço, mas sim, paga "para passar algum tempo participando de uma série de eventos memoráveis" (PINE; GILMORE, 1999, p.2). Com isso, não se compra algo com o intuito de que este exerça simplesmente sua função, mas sim, que possibilite satisfazer outros desejos a ele relacionados, indo ao encontro das idéias de Jensen (2002) e Marcuse (1968).

Assim, migrando para o turismo, o indivíduo não vai à praia apenas para tomar sol ou um banho de mar, mas também para ficar belo no conceito da sociedade, para relaxar, para encontrar os amigos. E passear por uma região de vinhedos vai além da degustação de vinhos ou da oportunidade de apreciar a paisagem, pois o turista busca um conjunto de sensações proporcionadas a todo instante, em todo momento que ele considera estar consumindo o produto turístico.

Acrescentar elementos que aumentem o uso dos sentidos com determinado produto pode ser a forma mais eficaz para se produzir sensações e emoções (PINE; GILMORE, 1999). Fazer com que o visitante participe de maneira mais ativa nos destinos turísticos facilita a construção de significados sobre o produto, bem como, gera um número maior de experiências e momentos inesquecíveis, favorecendo a satisfação do turista. As sensações obtidas no momento em que o cliente está consumindo um produto turístico são formas de agregar valor ao mesmo e, conseqüentemente, proporcionar um fluxo turístico maior, oportunizando lucratividade às empresas.

Estas adequações sob a ótica da produção possuem um objetivo claro: as empresas buscam a realização de lucros. Se antes as organizações trabalhavam com a chamada "economia de serviços" - aquela que deve gerar serviço, mas ainda não dava atenção para produção de encantamento - Beni (2003) aponta que a migração desse modelo econômico para a "economia da experiência" na área do turismo será condição de sobrevivência para as empresas do setor. Neste processo transitório, Carvalho (apud LOCKS, 2007) afirma que os vendedores de apartamentos em hotéis serão substituídos por 
vendedores de experiências; os criadores de pacotes deverão criar emoções; os comerciantes tornar-se-ão contadores de histórias; e os turistas - ah, os turistas - deixam de ser espectadores para se tornarem protagonistas neste novo cenário. É a reelaboração de um mesmo produto utilizando outros aspectos que podem influenciar a conquista de clientes.

Seguindo esta tendência que visa a oportunizar experiências únicas aos turistas e incrementar as vendas, o Ministério do Turismo, juntamente com o Sebrae Nacional e o Sindicato de Hotéis, Restaurantes, Bares e Similares da Região Uva e Vinho, implementou o projeto-piloto Economia da Experiência Vivências na Região Uva e Vinho. O projeto foi implantado em maio/2006, em oito municípios da região gaúcha: Bento Gonçalves, Garibaldi, Veranópolis, Vila Flores, Nova Prata, Cotiporã, Protásio Alves e Caxias do Sul. Nestes municípios, foram selecionadas 72 empreendimentos dos segmentos de gastronomia, vinícola, hospedagem, produção associada, produção cultural e entretenimento. Os objetivos do projeto estão voltados para a diversificação da oferta e conseqüentemente do consumo turístico, além de aumentar a geração de emprego e renda nas localidades envolvidas, formando uma rede de cooperação entre os diferentes negócios existentes (SEBRAE, 2007).

O principal produto turístico desenvolvido na região é o enoturismo, tipologia caracterizada pela visitação aos vinhedos, cantinas e festivais vinícolas, por aqueles que se interessam pela uva, pelo vinho e pelas mais diversas características de uma região vitivinícola, sejam elas naturais ou culturais (HALL; MACIONIS, 1998). A região figura como principal produtora de vinhos no país, produção essa relacionada à descendência dos imigrantes italianos, que marca aspectos da cultura local, também transformada em atrativo turístico (DE PARIS, 1999).

Ao buscar a proposta de comercializar o único, os empreendimentos turísticos ficam diretamente ligados à necessidade de atrativos que possuam diferenciais. O enoturismo, devido a sua essência conceitual, tem a possibilidade de envolver o visitante em uma atmosfera onde todas as experiências são tidas como únicas: o aroma da uva e o sabor dos vinhos são 
tão específicos do terroir ${ }^{2}$ quanto o modo de falar e o estilo de viver são próprios da localidade em questão. "Já pensou em colher cachos de uva no meio de parreirais? Ou, então, degustar vinho de olhos vendados e compartilhar as sensações e as lembranças que a experiência lhe faz sentir?" (SEBRAE, 2007, p.41).

Com base nestas e outras justificativas que implicam que o enoturismo é propício para o novo pensamento econômico, o projeto Economia da Experiência compreendeu visitas técnicas por profissionais de cada segmento das empresas envolvidas no projeto. Em um primeiro momento foi feito o levantamento de dados e elaboração de diagnósticos, para, posteriormente, serem propostas inovações a partir da realidade e da história de cada empresa, tendo sempre presente o objetivo de propiciar ao turista o consumo de sensações e emoções durante as visitações. Não foram inventados atrativos; na realidade as informações pré-existentes foram moldadas no intuito de proporcionar emoções ao visitante. Como resultado, as empresas adotaram algumas idéias e adaptaram outras que possibilitariam aumento no fluxo turístico.

O projeto foi colocado em prática e outras iniciativas similares estão ocorrendo em diferentes locais do país, incentivando empreendedores do turismo a comercializar um conjunto de emoções e não apenas um produto ou serviço. É a proposta de uma reinvenção na forma de como comercializar o turismo, setor econômico considerado dos mais promissores.

Mas qual o real significado do consumo de emoções, da economia da experiência na atual sociedade do sonho?

\footnotetext{
${ }^{2}$ O termo francês terroir está associado ao conjunto de solo, clima e exposição à luz que determinado espaço possui, tornando-o único e interferindo nas características do vinho produzido a partir das uvas ali cultivadas (CLARKE, 2002).
} 


\section{Economia da experiência: o consumo e suas condicionantes}

Embora de característica intangível, o turismo materializa-se através das formas fixas existentes nos destinos: atrativos turísticos, equipamentos e serviços turísticos, além da infra-estrutura de apoio. Dessa forma, produção e consumo ocorrem no mesmo local e, em algumas vezes, simultaneamente, visto que a produção compreende a execução de serviços ao visitante, conforme visto anteriormente (BENI, 2002; LEMOS, 2005).

Muitos são os motivos pelos quais um indivíduo decide realizar turismo: conhecimento, status, fuga da rotina, preenchimento do vazio. Podem estar relacionados a fatores externos, tais como política, cultura, economia, ou ainda pessoais, psicológicos, sociais (SWARBROOKE; HORNER, 2002). Independente do interesse, o viajante busca sua satisfação e, para tal, necessita despender um valor financeiro. Segundo Lemos (2005, p.178), "cada turista possui níveis de satisfação nos quais são definidas suas preferências, e uma renda que define sua restrição orçamentária".

Apesar desta crescente adequação econômica que busca a humanização dos produtos, através de emoções e sensações únicas que o visitante pode ter, as mesmas possuem um preço e, exatamente por isso, o turismo mantém-se como atividade excludente, tornando-se mais uma forma de consumo dos indivíduos na atualidade. No entanto, devido à importância do ato de consumir, Portuguez (2001) considera a existência de diferentes oportunidades de consumo, visto que são criados produtos para todas as camadas sociais, acompanhando suas possibilidades, fazendo com que todos possam comprar.

Conforme aponta Barretto (2003), os primeiros "turistas" (séculos XVI a XVIII) eram pessoas nobres, com poder e dinheiro. Após a década de 1950, o turismo passou a ser praticado por indivíduos pertencentes a uma classe média com muito poder aquisitivo. Além do dinheiro, o turismo exige que seu 
consumidor possua tempo livre, elemento que repercutiu após a Revolução Industrial e o uso da máquina a vapor, proporcionando às classes de menor poder aquisitivo a possibilidade de ocupação deste tempo em que não estariam trabalhando. Apesar destas transformações, estima-se atualmente que apenas $10 \%$ da população mundial compõem o cenário da demanda turística. Conforme identifica Barretto (2003, p.51), "como mais um produto da sociedade de consumo, o turismo é vendido a quem tem dinheiro".

Lemos (2005), ao analisar o turismo enquanto deslocamento de indivíduos sob o prisma da economia, conclui que o tempo livre concedido aos trabalhadores, elemento este sustentado pelo turismo como propulsor da atividade pós Revolução Industrial, não se liberta da lógica de reprodução de capital, pois seus gastos em viagens permitem a existência de produção turística e sua comercialização. Ainda com relação ao tempo livre, Portuguez (2001) o associa diretamente ao tempo de consumo, devido às necessidades criadas pela mídia e, é neste momento que se evidencia a importância de viajar sobrepondo outras atividades. Para Slatern (2002, p.36), isso significa que "a redefinição das horas de folga como horas de consumo, a transformação do lazer em mercadoria, tem sido crucial na manutenção do crescimento capitalista".

Cada vez mais as coisas se transformam em valor monetário. A "nova" economia apresenta, de fato, novos rumos para as empresas. Ensina a elaborar um preço, um valor, sobre algo intangível e, principalmente, como comercializar isto aos consumidores ávidos por satisfazer tantos desejos. Os conceitos da Economia da Experiência e da Sociedade dos Sonhos mostram que as emoções também podem ser comercializadas em forma de lembrança, e assim as empresas podem lucrar mais com isso (PINE; GILMORE, 1999; JENSEN, 2002).

A atenção e o cuidado do recepcionista ou do garçom tornam-se parte do produto comercializado e podem ser obtidos através de uma boa gorjeta. De um lado a demanda está disposta a remunerar quem compõe a oferta e está preparado para realizar o que possa satisfazer o turista. Certo está que na 
sociedade atual, não importa o que o indivíduo precisa satisfazer; terá que pagar por isso. Seja para saciar a fome de alimento, de conhecimento, para sair da rotina, consumir tornou-se imperativo.

Featherstone (1997) auxilia a compreensão quanto ao consumo e realiza uma análise que o identifica sob três óticas diferentes. Uma delas assinala que o consumo é resultado do capitalismo, alicerçado na produção e acumulação de riquezas. Tal produção precisa ser comercializada, ou seja, é mister criar novos mercados consumidores. Neste pensamento, o capitalismo sugere a existência de uma nova cultura: a cultura do valor de troca. Através dela, tudo possui um preço, pelo qual tudo pode e deve ser adquirido, desde o saco de arroz até o paraíso localizado em ilhas isoladas. De forma mais explícita, Slater reafirma estas idéias, pois na sua visão "cultura do consumo é cultura capitalista" (SLATER, 2002, p.33).

Ao considerar a atividade turística como uma forma de consumo, Lemos (2005) compartilha com as idéias dos autores citados e aponta que o turismo tem a necessidade de "aumentar a capacidade de acumulação de capital" (LEMOS, 2005, p.210) através da lógica de produção, consumo e relação salarial. O tipo de produto é indiferente neste modelo, o importante é que exista a comercialização. E no interesse de incrementar a comercialização as empresas desenvolvem estratégias para conquistar clientes, e enaltecer as experiências e emoções no momento do consumo pode ser enquadrado dentre as ferramentas atuais.

Quanto às estratégias da reprodução capitalista, Portuguez (2001, p.6) afirma que "as pessoas se comportam como marionetes, porque via de regra não questionam as tolas atitudes do dia-a-dia, que muitas vezes são exatamente os reflexos da vontade das altas esferas de 'gestão' da vida cotidiana". Os indivíduos seguem padrões sugeridos ou ainda impostos por detentores de poder, cujo interesse reside no modelo capitalista. E um destes padrões é a necessidade de consumir.

Uma segunda explicação de Featherstone (1997) para a existência do consumo estabelece que a aquisição de bens e mercadorias é vista como uma 
forma de distinção social, através de um fluxo constante de renovação de mercadorias. Constantemente são criados novos produtos, para que os indivíduos sintam a necessidade de adquirir o novo. Na visão de Portuguez (2001), o que num primeiro instante é símbolo de desejo e consumo da classe social com maior poder aquisitivo, em pouco tempo se torna produto consumido por estratos sociais inferiores.

Assim, novos produtos são criados buscando a adesão de pessoas de classes superiores que servem como referência quanto ao mesmo. Destinos que trabalham o chamado turismo alternativo, cujas características são antimassificação e devido a isso um produto de preço mais elevado, logo convertem-se em locais de consumo de indivíduos de outras classes sociais, seguindo a renovação de mercadorias proposta por Featherstone (1997).

Para Douglas e Isherwood (2004), o consumo é uma característica fundamental das sociedades urbanas e pós-industriais contemporâneas, ou seja, não estava presente nas sociedades de séculos passados. Mas Slater (2002) atenta para o fato de que o consumo é associado à produção em massa e por isso é visto como parte recente da história humana. No entanto, continua o autor, o consumo remete ao desdobramento de um sistema herdado de períodos bem anteriores, pois no século XIX já existiam críticas a respeito do consumismo. O consumo de hoje pressupõe a compra de uma gama de significados simbólicos que expressam pertencimento ao mundo social. Quando o indivíduo afirma que precisa de algo, faz duas declarações: primeiramente, que precisa disso para ter um certo tipo de vida, certas relações, e em segundo plano está declarando que tem recursos e direitos para isso (SLATER, 2002).

Desta forma, o indivíduo sente a necessidade de consumir algo para fazer parte de um grupo de amigos, dos colegas de trabalho, da comunidade onde reside, do mundo do qual faz parte. Bourdieu (2007) identifica estes elementos ao afirmar que as escolhas de compra, o gosto, podem classificar as pessoas, pois através dos produtos que um sujeito adquire está evidenciando 
seus valores, opiniões, suas referências perante as outras pessoas da sociedade.

Se até determinado momento na história, o ser humano trocava ou adquiria produtos tangíveis, a sociedade atual expressa de forma crescente o consumo de lugares, de bens intangíveis, associado a motivos dos mais diversos, como é o caso do turismo (URRY, 1996).

Independente da classe social e poder econômico, a compra de bens e serviços parece tornar-se condição de sobrevivência, conforme abordado anteriormente em Portuguez (2001). Compartilhando com este autor, Featherstone (1997, p.38) afirma que

[...] a oferta constante de novas mercadorias, objetos de desejo e da moda, ou a usurpação dos bens marcadores pelos grupos de baixo, produz um efeito de perseguição infinita, segundo o qual os de cima serão obrigados a investir em novos bens (de informação) a fim de restabelecer a distinção social original.

Considerando-se o consumo de produtos como uma forma de status e diferenciação, o turismo cria a todo instante destinos turísticos capazes de indicar a distinção das classes sociais e, indo além, fortalece a imagem de quem é quem no jogo de diferenças: o turista possui recursos e está usufruindo, enquanto aquele que está do outro lado sobrevive ao prestar um serviço e precisa constantemente do turista.

A terceira e última ótica apontada por Featherstone (1997) sobre o consumo é a que o envolve com os prazeres que pode proporcionar: a compensação pelo esforço do trabalho diário. É a promessa de que a disciplina e o sacrifício utilizados para a acumulação de riqueza são superados a partir do momento em que são atendidas as necessidades e prazeres do indivíduo através do ato de consumir.

Mas quando o assunto são as necessidades humanas, Baudrillard (1981) afirma que os seres sociais não adquirem bens ou serviços apenas para satisfazer suas necessidades ou desejos. Os consumidores compram uma série de elementos indicativos, possuidores de uma simbologia e representantes de um estilo, fazendo desta forma o consumo de signos (signos-mercadoria). 
TONINI, Hernanda. Economia da experiência: o consumo de emoções na Região Uva e Vinho. Revista Brasileira de Pesquisa em Turismo. v. 3, n. 1, p. 90-107, abril 2009.

É o seguinte o princípio da análise: nunca se consome o objeto em si (no seu valor de uso) - os objetos (no sentido lato) manipulam-se sempre como signos que distinguem o indivíduo, quer filiando-o no próprio grupo tomado como referência ideal, quer demarcando-o do respectivo grupo por referência a um grupo de estatuto superior (BAUDRILLARD, 1981, p.60).

Para o autor o consumo se dá de acordo com interesses alheios e prédeterminados pelo marketing, responsáveis pela criação da simbologia, dos signos que cada produto/serviço representa.

Contrariando Baudrillard (1981), Douglas e Isherwood (2004) afirmam que os consumidores têm a capacidade de manipular os bens simbólicos dentro de regras e códigos culturais elaborados por eles mesmos, ou seja, a criação dos signos não seria realizada por estereótipos formados por interesses de terceiros. Cada indivíduo consome elementos cuja simbologia refere-se a necessidades intrínsecas, e não desenvolvidas pela mídia.

Ao discutir algo tão complexo e subjetivo quanto o consumo e seus reais significados, cabe muito bem lembrar as palavras de Viveret (2006, p. 23), para quem "o problema fundamental do ser humano não está do lado das necessidades", mas sim, no desejo, um elemento ilimitado por natureza. Quando este desejo se orienta para o "ter", o indivíduo sobrepõe ao que está relacionado ao "ser". Nesta lógica, tudo torna-se mercadoria, o que Marx (1982) definia como sendo a ilusão sobre o produto forjada pelo capitalismo, passível de ser comercializada, como é o caso das emoções e experiências proporcionadas pelo turismo.

\section{Enoturismo e economia da experiência: o consumo de emoções}

Dentre os produtos de consumo, o turismo vem obtendo destaque através de uma série de tipologias comercializáveis: turismo cultural, turismo de aventura, turismo de praia, enoturismo etc. Cada tipologia possui características gerais da atividade e algumas específicas, responsáveis por 
definir o interesse dos turistas sobre determinada atividade, criando a motivação principal que gera o deslocamento. Segundo Featherstone (1991), com a crescente transformação da matéria original em elementos que podem ser adquiridos não apenas do cotidiano, o turismo torna-se um centro de consumo possuidor de mercadorias e experiências simbólicas. Ou seja, a visita a um museu torna-se um produto do turismo cultural, o rafting torna-se parte do turismo de aventura, a degustação de vinhos contempla o consumo do enoturismo, dentre tantas outras atividades.

Em pesquisa recente, Lavandoski (2008) identificou que a visitação aos vinhedos, a degustação de vinhos, o comércio de produtos locais e a gastronomia são os principais atrativos turísticos na região do Vale dos Vinhedos, principal rota enoturística do País, inserida em três municípios que fazem parte do Projeto Economia da Experiência - Vivências na Região Uva e Vinho. Com o desenvolvimento da atividade turística local, cada um destes atrativos tornou-se um bem de consumo para os turistas. Além disso, a autora identificou que consumir o enoturismo no Vale significa encontrar tranqüilidade e romantismo, signos criados através do marketing e da mídia para incrementar as vendas, indo ao encontro de Baudrillard (1981).

A paisagem típica da região vitivinícola comercializa o novo, o diferente, algo que proporciona lazer, descanso, contato com o meio ambiente e experiências prazerosas. Todos estes aspectos foram trabalhados nos objetivos do Projeto Economia da Experiência, que pode ser traduzido como um aperfeiçoamento dos elementos de consumo da região.

No Vale dos Vinhedos os visitantes são atraídos por algo que vai além de um simples consumo materialista; são atraídos pelo vinho que envolve tanto sentimentos, conhecimento $e$ as diferentes manifestações da cultura de um povo (LAVANDOSKI, 2008, p.88).

É este conjunto de elementos materiais e imateriais que são recortados e estruturados pelos empresários como produto turístico a ser consumido por aqueles que tem esta possibilidade, de acordo com os pré-requisitos do turismo, pois "a lógica do capital encontra nos elementos do valor turístico um 
espaço para a sua reprodução" (LEMOS, 2005, p.212). Assim, o Projeto desenvolvido na região enoturística alia a necessidade das empresas locais em incrementar suas vendas e o interesse dos indivíduos ávidos em consumir lugares e turismo sem, no entanto, analisar profundamente o planejamento da atividade no âmbito geral que esta atinge.

É o triunfo do signo aliado ao marketing; é o consumo de mercadorias, serviços e experiências produzidas exclusivamente para serem vendidas aos consumidores (SLATER, 2002), o que é facilmente identificado na comercialização dos produtos turísticos.

É a crescente preocupação do "ter" em detrimento do "ser"; a transformação do valor em moeda; é a necessidade ilimitada, o desejo constante e a produção de mais desejos para determinar a ordem e o progresso econômico, que vem ditando as regras e normas da sociedade atual mundial.

\section{Considerações finais}

Através de bibliografia, pesquisas e projetos existentes sobre a Economia da Experiência ou Sociedade dos Sonhos, não estamos diante de uma "nova" tendência econômica que emerge nos mais diferentes setores. Pode-se inferir que esta é mais uma tentativa de estimular os preceitos do capitalismo, fortalecendo a cultura de consumo da sociedade atual. Economia da experiência nada mais é que a tradução do consumo de signos, onde o elemento diferenciador, o exótico, o único, se transforma em emoções que traduzem símbolos sociais, distinções e fortalecem a importância do "que tenho" perante "quem sou". Até porque "quem sou" só é mostrado através do "que tenho".

O conjunto de sensações e emoções expresso como momentos únicos - a economia da experiência - não pode ser compreendido como uma 
experiência econômica (em termos financeiros) no que tange à atividade turística. Conforme abordado, o turismo exige dinheiro e quanto maior valor agregado para se vivenciar uma experiência única, mais caro torna-se o produto. Assim, os preços praticados no Vale dos Vinhedos, região pertencente ao projeto discutido no presente artigo, sofreram uma alteração crescente devido à demanda turística e ao aprimoramento da oferta, paralelo ao aumento do custo de vida da população local, que se reflete, como exemplo, na especulação imobiliária sobre terras com fins rurais (TONINI, 2007).

Conforme Barretto (2003, p.26) defende, "o grande paradoxo do turismo é que essa atividade coloca em contato pessoas que não enxergam a si mesmas como pessoas, mas como portadores de uma função precisa e determinada". A transformação dos valores em mercadoria demonstra que não buscamos mais a essência das coisas e seus reais significados, mas sim adquirimos produtos sem conteúdo, apenas pela aparência que os mesmos apresentam ou podem nos apresentar.

Assim, enquanto existirem pesquisas e projetos que enfatizam o turismo focando apenas seu lado econômico, será dado continuidade ao pensamento capitalista em que os protagonistas são vistos como meros cumpridores da função de produção - empresas turísticas - e consumo turistas - e não como seres que possuem emoções e sentimentos alicerçados nos inter-relacionamentos, passíveis de efeitos positivos ou negativos para os próprios indivíduos participantes ou ainda para a comunidade como um todo.

\section{Referências bibliográficas}

BARRETTO, Margarita. O imprescindível aporte das ciências sociais para o planejamento e a compreensão do turismo. Horizontes Antropológicos. ano 9. n.20, p.15-29, 2003.

BAUDRILLARD, Jean. A sociedade de consumo. Lisboa: Edições 70, 1981.

BENI, Mário C. Análise estrutural do turismo. 7. ed. São Paulo. SENAC, 2002. 
TONINI, Hernanda. Economia da experiência: o consumo de emoções na Região Uva e Vinho. Revista Brasileira de Pesquisa em Turismo. v. 3, n. 1, p. 90-107, abril 2009.

. Globalização do turismo: megatendências do setor e a realidade brasileira. São Paulo: Aleph, 2003.

BOURDIEU, Pierre. A distinção: crítica social do julgamento. São Paulo: Edusp, 2007.

CLARKE, Oz. Oz Clarke's wine atlas: wines and wine regions of the world's great vineyard areas. 2 ed. London: Little Brown, 2002.

CONNELLAN, Tom. Nos bastidores da Disney: os segredos do sucesso da mais poderosa empresa de diversões do mundo. São Paulo: Futura, 2002.

DE PARIS, Assunta (coord.). Memórias: Bento Gonçalves - 109 anos. Bento Gonçalves: Prefeitura Municipal de Bento Gonçalves, Arquivo Histórico Municipal, 1999.

DOUGLAS, Mary; ISHERWOOD, Baron. 0 mundo dos bens: para uma antropologia do consumo. Rio de Janeiro: UFRJ, 2004.

FEATHERSTONE, Mike. Cultura de consumo e pós-modernismo. São Paulo: Studio Nobel, 1997.

HALL, C. Michael; MACIONIS, Niki. Wine tourism in Australia and New Zealand. In: BUTLER, R. HALL, C. Michael. JENKINS, J. Tourism and recreation in rural areas. New York: John Wiley \& Sons, 1998.

JENKINS, Carson L.; LICKORISH, Lionard J. Introdução ao turismo. Tradução de Fabíola Carvalho S. Vasconcellos. Rio de Janeiro: Campus, 2000.

JENSEN, Rolf. The dream society 2: heartstorm. JP Boger, 2002.

LAVANDOSKI, Joice. A paisagem na rota enoturística Vale dos Vinhedos (RS), na perspectiva do visitante. Dissertação (Mestrado em Turismo). Universidade de Caxias do Sul. Caxias do Sul, 2008.

LEMOS, Leandro de. 0 valor turístico na economia da sustentabilidade. São Paulo: Aleph, 2005.

LOCKS, Eliza B.D. Prestação de serviços personalizados. Palhoça: Unisul Virtual, 2007.

MARCUSE, Herbert. A ideologia da sociedade industrial. Rio de Janeiro: Jorge Zahar, 1968.

MARX, Karl. O capital. 7.ed. Rio de Janeiro: LTC, 1982.

PINE II, Joseph; GILMORE, James H. O espetáculo dos negócios: desperte emoções que seduzam os clientes, sensações intensas determinam o valor de produtos e serviços. 2 ed. Rio de Janeiro: Elsevier, 1999.

PORTUGUEZ, Anderzon Pereira. Consumo e espaço: turismo, lazer e outros temas. São Paulo: Roca, 2001.

SEBRAE. Vinhos brasileiros: o mundo degusta o Brasil. Brasília: Athalaia, Dezembro/2007. 
SLATER, Don. Cultura do consumo e modernidade. São Paulo: Nobel, 2002.

SWARBROOKE, John. HORNER, SUsan. O comportamento do consumidor no turismo. São Paulo: Aleph, 2002.

TONINI, Hernanda. Estado e turismo: políticas públicas e enoturismo no Vale dos Vinhedos. Dissertação (Mestrado em Turismo). Universidade de Caxias do Sul. Caxias do Sul, 2007.

URRY, John. O olhar do turista: lazer e viagens nas sociedades contemporâneas. São Paulo: Studio Nobel, 196.

VIVERET, Patrick. Reconsiderar a riqueza. Tradução Vera Ribeiro. Brasília: Editora Universidade de Brasília, 2006. 